\title{
Self Determination and Health Behaviors in Children with Cystic Fibrosis
}

\author{
Peter M. Bingham ${ }^{*}, 1$ and Matthew Meyer ${ }^{2}$ \\ ${ }^{1}$ Department of Neurology and ${ }^{2}$ School of Medicine, University of Vermont, Burlington, VT 05401, USA
}

\begin{abstract}
Purpose: We interviewed pediatric patients with cystic fibrosis (CF) to plan an intervention that would support adherence to respiratory therapies while also promoting self-determination. Interviews were structured so as to assess our hypothesis that patients experience less self-determination in the context of their health care compared to other activities.

Methods: We conducted a qualitative interview study to characterize CF patients' sense of competence, autonomy, and relatedness in the areas of health care behaviors, recreational activities, and other activities of daily life. Interviews were performed with seventeen, 8 to 16 year old children and adolescents with CF.

Results: Although subjects described similar levels of competency in the practice of healthcare activities compared to other daily activities, most reported relatively lower levels of autonomy and relatedness when discussing respiratory therapies compared to other daily activities.

Conclusion: Failure to meet patients' needs for autonomy and relatedness may represent potential barriers to treatment adherence in these adolescent and pre-adolescent subjects with CF. Our CF patients relate to recreational activities as supporting their competence and relatedness.
\end{abstract}

Keywords: Adherence, motivation, cystic fibrosis, respiratory therapy, qualitative research.

\section{INTRODUCTION}

People with Cystic Fibrosis (CF), like those with other chronic illnesses, must often follow intensive, long-term treatment plans. Current standard medical care imposes a rigorous regimen on these patients, including polypharmacy, complex dosing schedules, and respiratory therapies requiring hours per day. While treatments for CF increase quality [1-4] as well as length of life [5-7], the success of these therapies depends upon the effort and adherence of the patient [8]. Adherence to medical therapies is known to be poor in $\mathrm{CF}$, as it is in other chronic pediatric respiratory diseases [9]. Improving adherence to medications and treatments would improve the efficacy of many standard regimens for these conditions [10].

Recent qualitative studies identified consistent family support, patients' sense of long term benefits, and patients' sense of normalcy as important contributors to motivation and adherence $[9,11,12]$. Parents of children with $\mathrm{CF}$ identified more conflict associated with more timeconsuming treatments. Children with $\mathrm{CF}$ frequently identified trouble swallowing, and bad taste as barriers to adherence [13]. Respiratory therapies are especially timeconsuming and require behaviors and postures that distinguish the patient as ill relative to peers. Similar psychosocial factors impede adherence in children with asthma [14]. Prior studies have thus identified important pragmatic barriers to compliance, without identifying motivational factors, or incorporating an overall model for behavior change.

*Address correspondence to this author at the Department of Neurology, University of Vermont, Burlington, VT 05401, USA;

Tel: 802-847-3749; Fax: 802-847-8742;

E-mail: Peter.Bingham@vtmednet.org
Self-Determination Theory (SDT) identifies individuals' needs for a sense of competence, autonomy and relatedness as building blocks for intrinsic motivation. Competence is "one's ability to deal effectively with his or her surroundings," and enables creativity and resourcefulness in challenging situations [15]. Autonomy is one's sense that he or she is the unique origin of his or her behaviors and will 'cherish that behavior and its results' [16]. Relatedness refers to one's feeling of belonging, with the expectation of frequent, positive interactions in a caring environment [17]. In the clinical arena, SDT predicts that interventions with the best chance of promoting adherence will be those meeting these needs [18].

As part of a project aimed to develop digital games for children with $\mathrm{CF}$ that would support their engagement with breathing techniques for airway clearance, we carried out a series of structured interviews of adolescent patients that were intended to assess the degree of intrinsic (i.e., selfdetermined) versus extrinsic (i.e., compelled or coerced) motivation in these patients regarding health behaviors. We tried to learn what barriers interfere with subjects' needs for competence, autonomy, and relatedness in their adherence to prescribed medical regimes. We also inquired about recreational and other daily activities. Since healthcare routines are often inimical to individuals' immediate sense of self-determination, we expected our pediatric CF patients to associate less self-determination with healthcare behaviors compared to other areas of their daily experience.

\section{METHODS}

We interviewed a convenience sample of 17 children, pre-teens, and teens (8-16 year old) with a confirmed diagnosis of CF (see Table 1). Those interviewed were sampled from the pediatric patients attending the CF clinic at 
Fletcher Allen Health Care (FAHC) in Burlington, VT and those admitted to the hospital at FAHC for acute exacerbations of $\mathrm{CF}$. All procedures were approved by the University of Vermont's Institutional Review Board.

\section{Recruitment}

We sent an introductory mailing with a request for an interview along with the reminder for the quarterly clinic appointment to a convenience sample of candidates eligible for the interviews. On arrival to the clinic, and when convenient for the subject/family, the researcher approached the candidates and their families with additional information about the nature and goals of the study as well as consent forms. All individuals who received mailings and were approached in clinic consented to be interviewed. Interviews began immediately once the child assented and the family consented to participate.

\section{Subjects and Interviews}

Subjects were 17 pre-adolescents and adolescents from the FAHC CF clinic where they had periodic follow-up care.

Table 1. Subject Demographics

\begin{tabular}{|c|c|c|c|}
\hline Interviewee & Age (Yrs) & Gender & Ethnicity \\
\hline \hline 1 & 16 & M & Caucasian \\
\hline 2 & 16 & F & Caucasian \\
\hline 3 & 16 & M & Caucasian \\
\hline 4 & 14 & F & Caucasian \\
\hline 5 & 10 & M & Caucasian \\
\hline 6 & 13 & M & Caucasian \\
\hline 7 & 14 & M & Caucasian \\
\hline 8 & 15 & M & Caucasian \\
\hline 9 & 12 & M & Caucasian \\
\hline 10 & 13 & F & Caucasian \\
\hline 11 & 8 & F & Caucasian \\
\hline 12 & 16 & F & Caucasian \\
\hline 13 & 14 & M & Caucasian \\
\hline 14 & 14 & F & Caucasian \\
\hline 15 & 9 & F & Caucasian \\
\hline 16 & 15 & M & Caucasian \\
\hline 17 & 12 & M & Caucasian \\
\hline
\end{tabular}

These individuals all were involved with complex treatment protocols that included: nebulizers, airway clearance vests, 'hands-on' respiratory therapy, inhalers, antibiotics, digestive enzymes, hypertonic saline, oscillating positive-expiratory pressure devices, and vitamins. A structured guide (see appendix) for interviews was developed from an initial pilot study of a breath-controlled video game for hospitalized pediatric patients with CF. Interviews were oriented towards (1) identifying barriers to adherence with prescribed respiratory therapies (defined here as inhaled medications, percussion physiotherapy, and breathing techniques including active cycle breathing or huffing); (2) identifying recreational activities of pediatric CF patients, including engagement with digital media; (3) identifying attitudes about $\mathrm{CF}$ and its treatment in general. Three cycles of iterative refinement of our structured interview were performed in the course of this pilot experience, leading to a final version used for the present study. The interview began by engaging children with discussion questions about free time, followed by questions regarding healthcare experience. To this structured interview, we added a survey that has been validated and used in clinical populations in the SDT literature. Survey questions regarding self-determination were obtained from the authors' website (http://www.psych.rochester.edu/SDT/ questionnaires.php) [19]. The interviews also addressed respondents' recreational activities, including respondents' preferences for context and content in video games. Interviews were performed at clinical (in- or out-patient) spaces, with parents present, by one of the authors (MM) who was also trained in interviewing skills by an individual with extensive experience in qualitative research, interviewing, and conducting focus groups.

\section{Data Collection}

Twelve interviews were conducted in the ambulatory clinic and five in the in-patient setting. Interviews lasted between 15 and 30 minutes; they were digitally recorded and later transcribed for review. Following the interview, participants answered a written SDT survey; five of the younger participants had the survey read to them and verbally responded.

\section{Data Analysis}

Digital recordings were transcribed excepting identifying remarks. A qualitative analysis of the data included abstraction of responses and categorization according to their alignment with the constructs of competence, relatedness, and autonomy. Survey results were tabulated.

\section{RESULTS}

\section{Competence}

When subjects were asked to rate between 1 (poor) and 10 (great) how well they were doing their treatments, all but two respondents ranked a 7 or greater. Most subjects considered their knowledge and performance of their treatment regimens to be strong. Frequently, subjects cited the importance of their medicines as a reason why they did their routines so well. When subjects admitted to lapses, they were largely unintentional and often related to social, athletic or family-based interruptions in their routines. While subjects stated they were doing a good job with their CF regimens, only nine subjects reported any awareness of 'huffing,' an autogenic clearance breathing technique recommended to all of our CF patients. Only three subjects practiced huffing on a regular basis. Others who were aware of the technique cited "cough," "dizziness," "lightheaded[ness\}" and a lack of efficacy as reasons for not doing it.

\section{Autonomy}

Subjects repeatedly mentioned $\mathrm{CF}$ treatments as something they "have to do" and over which they had "no 
choice," and parents or doctors were the reason they took their medications. Only five subjects mentioned taking their medications as something they "really want to [do]." When asked about which parts of their life were affected because of their CF, 13 of 17 responded "nothing", "none" or "no different."

Subjects often presented scenarios of passive or resistant responses to health care behaviors - when asked how one would get a participant to do something they did not want to do, most participants said they responded best to either a bribe or threat. When participants were asked what they disliked about their treatments, time was the most common response. One subject admitted to purposefully not taking prescribed medication. Otherwise, subjects' attitude towards medicine was one of acceptance. Although all subjects knew treatments were supposed to improve health, only one subject reported feeling an immediate improvement to inhaled medication. Subjects rarely expressed outwardly negative attitudes towards their treatments but nearly half complained about the amount of time required to administer the regimen, citing this as a reason for missing treatments.

The SDT Likert-scale survey (see appendix) helped to further elaborate upon the subjects' responses to questions of choice. There was a trend for subjects to endorse statements that external forces, and not personal volition, dictated their daily actions (Item \#4). Furthermore, subjects often felt coerces in daily activities (Items \#5, \#6). Still, subjects agreed that they had some free-choice in their life (\#7). The question prompt \#8 "What I do is often not what I'd choose to do" seemed often to have been misunderstood by participants, as responses to this question were inconsistent with responses given to other similar questions.
SDT survey questions focused on autonomy (see Appendix for numbered items corresponding to Tables $\mathbf{2}$ and 3 and Figs. 1, 2) yielded a mixture of responses, with a definite theme of lack of autonomy in connection with health behaviors. Subjects did not generally report feeling guilty about not taking medicine (\#9), and did not report feeling pressure from others (\#13) to take their medicine. Subjects were motivated to take their medicine in order to help them improve their personal health (\#10, \#15), and were also mindful not to upset others (\#11) by not adhering. Subjects acknowledged a desire to adhere so as to impress others (\#16) and their doctor (\#17, \#18). Internal inconsistencies in responses suggested that Item 12 ("I really don't think about it"), Item 14 ("Because it is easier to do what I am told than to think about it"), and Item 19, ("I don't really know why") were frequently misunderstood by subjects. Almost universally, subjects mentioned leisure activities as an area in which they had great freedom to choose. Non-treatment activities in which subjects felt as though they had the least choice were school, homework and chores.

\section{Table 2. Self-Determination Questions}

\begin{tabular}{|l|}
\hline I do what I have to, but I don't feel like it is really my choice \\
\hline I do what I do because it interests me \\
\hline I do what I do because I have to \\
\hline I am free to do whatever I decide to do \\
\hline What I do is often not what I'd choose to do \\
\hline
\end{tabular}

Subjects acknowledged playing videogames daily, with an estimated daily usage ranging from 30 minutes to $10-12$ hours; only two subjects played video games less than once

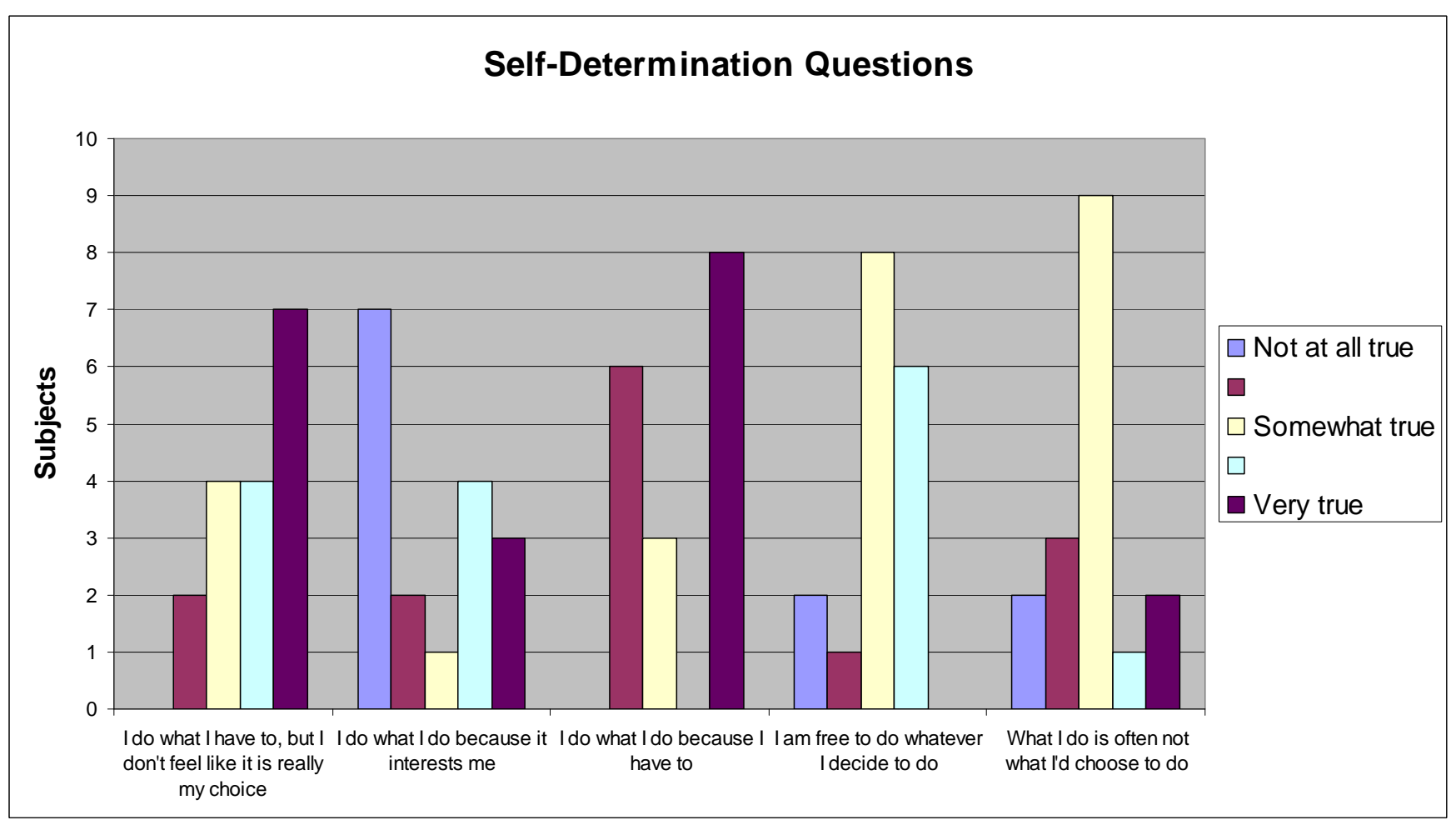

Fig. (1). Subjects' responses to self-determination questions on survey (see supplementary material). 


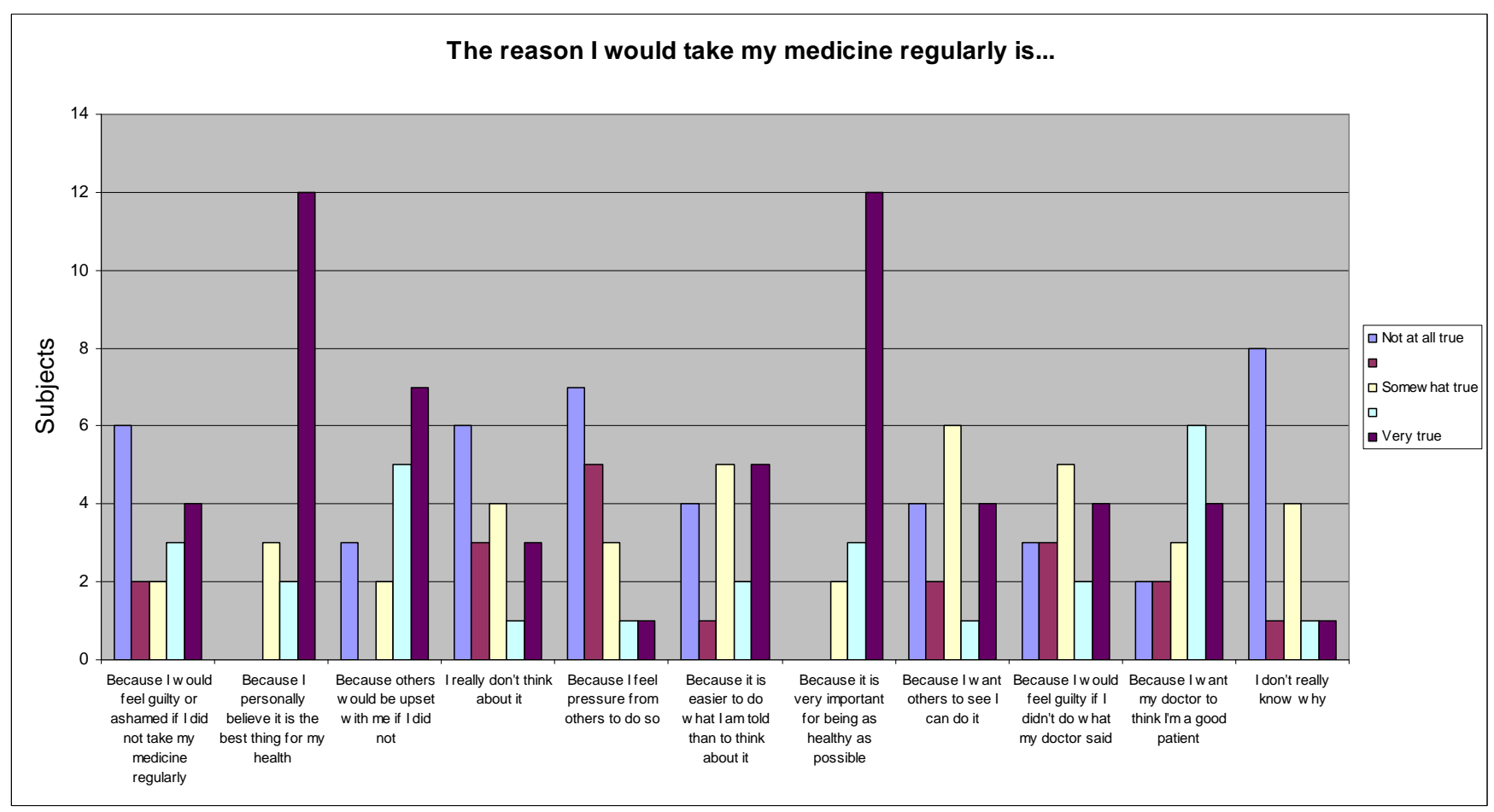

Fig. (2). Subjects' survey responses to the statement "The reason I would take my medicine regularly is..."

per week. Ten of 17 subjects used a video game, computer or television to occupy themselves during their daily treatment routines. Subjects frequently identified choice in the types of video games, and how they play the video games, including choices made during game play. Many of the subjects who denied frequent video game use at home mentioned video games as a preferred activity when admitted to the hospital.

Table 3. The Reason I would Take my Medication Regularly is...

\begin{tabular}{l} 
Because I would feel guilty or ashamed if I did not take my medicine \\
regularly \\
Because I personally believe it is the best thing for my health \\
Because others would be upset with me if I did not \\
\hline I really don't think about it \\
\hline Because I feel pressure from others to do so \\
\hline Because it is easier to do what I am told than to think about it \\
\hline Because it is very important for being as healthy as possible \\
\hline Because I want others to see I can do it \\
\hline Because I would feel guilty if I didn't do what my doctor said \\
\hline Because I want my doctor to think I'm a good patient \\
\hline I don't really know why \\
\hline
\end{tabular}

\section{Relatedness}

Participants repeatedly identified issues of social isolation associated with time-consuming CF treatment regimens: feelings of social isolation as a consequence of having $\mathrm{CF}$ and associated treatments were expressed by nearly half of the subjects. Masks for delivering nebulized medicine stopped the participants from talking, and vibratory vests kept them from hearing. Still, subjects tended to consider themselves as similar to their peers, repeatedly emphasizing their normality relative to their peers. This attitude was notably associated with gaming -- many subjects commented on social aspects of video gaming. Videogames were often mentioned as a preferred activity with friends. Even the subjects who infrequently played video games, mentioned friends as a common part of their video game experiences.

Non-medical activities were often an opportunity for respondents to be with their friends and family and to have choice in their behavior. Subjects participated in a variety of activities with their friends, and commented that they had choice in selecting who their friends were and when they could "hang-out" with them. Friends were mentioned as visitors to the hospital who provided entertainment and respite from the monotony of a hospital stay. When asked about friends with CF, interviewees repeatedly described limitations on contact with other patients. Outside of immediate family members with the disease and socializing inside of the hospital, relationships between children with CF were rare. Patients frequently cited the "three-foot rule" (intended to decrease communicable disease transmission) as a barrier to developing friendships with or interacting with other children with $\mathrm{CF}$.

\section{DISCUSSION}

To identify obstacles and supports to self-management in pediatric subjects with $\mathrm{CF}$, we conducted interviews addressing three central aspects of self-determination theory: subjects' sense of competence, autonomy, and relatedness in their daily lives. While the sample size was relatively small, the results reflect consistency in the attitudes and beliefs of 
adolescents and pre-teens with $\mathrm{CF}$ in these areas. These preliminary findings suggest relative strength in respondents' sense of competence, but weaknesses in respondents' sense of autonomy and relatedness in the context of their daily health care routines. In other areas of their lives such as sports activities, and engagement with digital media, subjects voiced a greater sense of autonomy and relatedness. These results provide groundwork for theory-driven design of interventions that could support self-management skills and health behaviors such as airway clearance exercises.

Subjects described competence in all parts of their lives including their healthcare. Whether it was school, play, work or health care, subjects reported feeling capable in all environments. We identified subjects' sense of competence in their sense of being "normal" relative to peers, a finding that has been noted in other interview studies in pediatric CF patients [20]. Considering CF treatment regimens, a ubiquitous component of subjects' lives, all were actively involved in their routines and most took primary responsibility for their medications and treatments. Subjects believed they were doing a good job, despite rarely noticing any physical improvement associated with their regimen. Moreover, subjects hardly ever felt negatively towards their medications, and when they missed doses, they cited forgetfulness, sleepiness or time-limitations as reasons. An incidental finding relating to adherence was that subjects only rarely reported immediate symptomatic relief following $\mathrm{CF}$ medications and treatments. Interventions aimed to promote self-managing health behaviors could build on subjects' sense of competence as it can in turn encourage creativity, perseverance [15], and can support intrinsic motivations for health behaviors [21].

As expected, feelings of autonomy did not fully extend to health behaviors. Subjects carried out their treatment routines with a sense of imposed necessity. Compounding the irritating qualities of their medicines (bad tastes, many pills, loud noises, oral obstruction), reported parental tactics aimed to increase adherence (i.e., nagging, restriction of privileges, and earning of gifts) had a strong "extrinsic" quality. Bribes, punishments, parents' insistence (extrinsic motivators) were cited more often than intrinsic motivators, such as a desire to maintain health. While most subjects indicated an extrinsically motivated relationship to their medication regimes ("something I have to do"), they accepted this necessity without apparent resentment. This impression is corroborated by results of the standardized SDT survey used to assess individuals' level of selfdetermination in relation to their own healthcare. On the other hand, a majority of subjects cited the reason as "for my health" instead of "for the doctor" when asked why they would take their medicine regularly, indicating a sense of personal responsibility and a sense of autonomy relating to performing complex daily treatment regimes.

Most subjects felt there was no difference between themselves and their peers, an attitude of "feeling normal" that accords with previous research [20]. Subjects had friends with whom they played on sport teams, visited while in the hospital, played video games, and just "hung-out."
None of the subjects reported having friends with CF, citing the "three foot rule" regarding contact with other "CFers". Subjects thus showed a clear sense of the impact of this restriction on their relatedness to peers with $\mathrm{CF}$, even as they were aware of the importance of containing the spread of pathogens.

Impacts upon social-life were a common complaint of subjects regarding CF treatment regimens. Medications and treatments were a common source of conflict between parents and subjects as noted above. Most subjects literally began and ended each day with their CF regimen, and had multiple hours throughout every day dedicated to medications and treatments; hours that subjects felt were essentially taken away from preferred activities and time to be with friends and family [22]. These interviews elucidate ways that $\mathrm{CF}$ treatments are inherently socially isolating: airway clearance vests are loud, and the nebulizers block the mouth and prevent speaking. Medical regimes (i.e. antibiotics, enzymes, inhalers) and equipment (i.e. vests, nebulizers) precluded some subjects from spending the night at friends' houses. Individuals with $\mathrm{CF}$ have limited opportunities to relate to others whose lives involve similar impositions. Interventions to improve adherence may be more effective if they can address these obstacles to autonomy and relatedness.

Our study is limited by small sample size-the sociocultural homogeneity of our study group renders the results preliminary. SDT-related questions were not intelligible (in the sense of age-appropriateness) to some of our younger subjects, some of whom did not relate to the reflections called for in the SDT survey. While these survey instruments have been used and validated in other populations, we did not identify earlier reports using SDT surveys in subjects with $\mathrm{CF}$, and few researchers have used SDT surveys in pediatric patients. SDT survey items may have cultural biases, or have belied the complexity of respondents' feelings about SDT themes: subjects' responses to the questions were incongruent with statements endorsed in other parts of the survey, or expressed to the interviewer at the time of the survey. Although they were developed after a series of earlier interviews with other subjects, non-SDT interview questions were not validated in a larger group. We did not characterize subjects according to disease severity or family environment, and we did not carry out independent verification of the qualitative analyses. Generalizability is limited by the considerations that all subjects were Caucasian, recruited from a single $\mathrm{CF}$ center with a catchment including a largely rural population. The interviews were conducted by clinical personnel in a clinical setting, although the consistency of responses we obtained suggests that this did not significantly affect interview results.

Most of the subjects were already using televisions, computers or video-game systems to entertain themselves while participating in their treatment routine. Video games can facilitate communication and relationships among children and adolescents with CF [23]. Most subjects reported playing for an hour or more per day, an amount 
similar to their cohort in the general population [24]. Subjects often mentioned having friends over to play video games, using video games to cope with hospitalization, and playing video games online with others. Video games thus represent opportunities for socialization in a clinical population at risk for social isolation.

Two recent efforts to increase treatment participation of patients' with $\mathrm{CF}$ included motivational interviewing [25] and web-based, cell phone reminders and information [26]. These interventions showed initial promise but required significant resource investment to implement. In adolescents with oncologic disease, patients were given a video game which required players to ensure adherence of virtual patients to oncologic treatment regimens in order to complete missions. This digital game-based intervention led to significant improvement in treatment adherence [27]. Our children and adolescents with CF have a strong affinity to video games. Based on our findings and these related reports, we would consider that a CF-oriented digital game could support patients' sense of competence, relatedness, and autonomy. This approach has potential to foster selfmanagement and adherence in this clinical population [28]. If electronic games were to be adapted to support health behaviors and self-management (for example see ref. 27), it will also be important to consider potential negative effects of these activities (e.g., sedentism, game addiction) [29].

Considering that "Only a small proportion of the variance in adherence has been accounted for in the literature [30]," continued patient-centered study of obstacles to selfmanagement are needed. As clinicians seek to maximize the benefits of medical treatments, the principles of SDT offer a framework for a patient-centered assessment of the impact of treatments on patients' lives. Our results offer insight as to how treatments can inadvertently confound patients' sense of competence, autonomy and relatedness. In principle, alignment of health behaviors with patients' psychological needs for self-determination will increase adherence and self-management.

\section{ACKNOWLEDGEMENTS}

Anne Dorwaldt provided guidance for the development and conduct of structured interviews. We thank Dr. Thomas Lahiri and the staff of the Vermont Children's Hospital Cystic Fibrosis Clinic, and the participants and their families for their openness and generosity.

\section{DECLARATION OF INTEREST}

Supported by a grant from the Robert Wood Johnson Foundation.

\section{SUPPLEMENTARY MATERIAL}

This article also contains supplementary material that can be viewed at publisher's website.

\section{REFERENCES}

[1] Anton DT, Moraru D, Cirdei E, Bozomitu L. [Malnutrition and complex nutritional therapy in cystic fibrosis]. Rev Med Chir Soc Med Nat Iasi 2006; 110(4): 801-6.
[2] Tarran R, Donaldson S, Boucher RC. Rationale for hypertonic saline therapy for cystic fibrosis lung disease. Semin Respir Crit Care Med 2007; 28(3): 295-302.

[3] Pesut D, Ciobanu L, Nagorni-Obradovic L. Pulmonary rehabilitation in chronic respiratory diseases--from goals to outcomes. Pneumologia 2008; 57(2): 65-9.

[4] Weiner JR, Toy EL, Sacco P, Duh MS. Costs, quality of life and treatment compliance associated with antibiotic therapies in patients with cystic fibrosis: a review of the literature. Expert Opin Pharmacother 2008; 9(5): 751-66.

[5] Corey M, McLaughlin FJ, Williams M, Levison H. A comparison of survival, growth, and pulmonary function in patients with cystic fibrosis in Boston and Toronto. J Clin Epidemiol 1988; 41(6): 58391.

[6] Davis PB. Cystic fibrosis since 1938. Am J Respir Crit Care Med 2006; 173(5): 475-82.

[7] Frederiksen B, Lanng S, Koch C, Hoiby N. Improved survival in the Danish center-treated cystic fibrosis patients: results of aggressive treatment. Pediatr Pulmonol 1996; 21(3): 153-8.

[8] O'Sullivan BP, Flume P. The clinical approach to lung disease in patients with cystic fibrosis. Semin Respir Crit Care Med 2009, 30(5): 505-13.

[9] Williams B, Mukhopadhyay S, Dowell J, Coyle J. Problems and solutions: accounts by parents and children of adhering to chest physiotherapy for cystic fibrosis. Disabil Rehabil 2007; 29(14): 1097-105.

[10] Haynes RB, Yao X, Degani A, et al. Interventions to enhance medication adherence. Cochrane Database Syst Rev 2005(4): CD000011.

[11] Brumfield K, Lansbury G. Experiences of adolescents with cystic fibrosis during their transition from paediatric to adult health care: a qualitative study of young Australian adults. Disabil Rehabil 2004; 26(4): 223-34

[12] Bucks RS, Hawkins K, Skinner TC, et al. Adherence to treatment in adolescents with cystic fibrosis: the role of illness perceptions and treatment beliefs. J Pediatr Psychol 2009; 34(8): 893-902.

[13] Modi AC, Quittner AL. Barriers to treatment adherence for children with cystic fibrosis and asthma: what gets in the way? J Pediatr Psychol 2006; 31(8): 846-58.

[14] Cohen R, Franco K, Motlow F, Reznik M, Ozuah PO. Perceptions and attitudes of adolescents with asthma. J Asthma 2003; 40(2): 207-11

[15] Deci EL. Intrinsic motivation. New York: Plenum Press 1975.

[16] DeCharms R. Personal causation; the internal affective determinants of behavior. New York: Academic Press 1968.

[17] Baumeister R, Leary M. The need to belong: desire for interpersonal attachments as a fundamental human motivation. Psychol Bull 1995; 117(3): 497-529.

[18] Deci EL, Ryan RM. The "what" and "why" of goal pursuits: Human needs and the self-determination of behavior. Psychol Inq 2000; 11(4): 227-68.

[19] Ryan RM, Connell JP. Perceived locus of causality and internalization: examining reasons for acting in two domains. J Pers Soc Psychol 1989; 57(5): 749-61.

[20] Williams B, Corlett J, Dowell JS, Coyle J, Mukhopadhyay S. I've never not had it so I don't really know what it's like not to: nondifference and biographical disruption among children and young people with cystic fibrosis. Qual Health Res 2009; 19(10): 1443-55.

[21] Ryan RM, Deci EL. Self-determination theory and the facilitation of intrinsic motivation, social development, and well-being. Am Psychol 2000; 55(1): 68-78

[22] Badlan K. Young people living with cystic fibrosis: an insight into their subjective experience. Health Soc Care Community 2006; 14(3): 264-70.

[23] Tierney S, Deaton C, Webb K, et al. Isolation, motivation and balance: living with type 1 or cystic fibrosis-related diabetes. J Clin Nurs 2008; 17(7B): 235-43.

[24] Cummings HM, Vandewater EA. Relation of adolescent video game play to time spent in other activities. Arch Pediatr Adolesc Med 2007; 161(7): 684-9. 
[25] Duff AJ, Latchford GJ. Motivational interviewing for adherence problems in cystic fibrosis. Pediatr Pulmonol 2010; 45(3): 211-20.

[26] Marciel KK, Saiman L, Quittell LM, Dawkins K, Quittner AL. Cell phone intervention to improve adherence: cystic fibrosis care team, patient, and parent perspectives. Pediatr Pulmonol 2010; 45(2): $157-64$.

[27] Kato PM, Cole SW, Bradlyn AS, Pollock BH. A video game improves behavioral outcomes in adolescents and young adults with cancer: a randomized trial. Pediatrics 2008; 122(2): e305-17.
[28] Ryan RR, Rigby CS, Przybylski A. The motivational pull of video games: A self-determination theory approach. Motiv Emot 2006; 30(4): 347-63.

[29] Gentile D. Pathological video-game use among youth ages 8 to 18 : a national study. Psychol Sci 2009; 20(5): 594-602.

[30] Kettler LJ, Sawyer SM, Winefield HR, Greville HW. Determinants of adherence in adults with cystic fibrosis. Thorax 2002; 57(5): 459-64.

(C) Bingham and Meyer; Licensee Bentham Open.

This is an open access article licensed under the terms of the Creative Commons Attribution Non-Commercial License (http://creativecommons.org/licenses/by$\mathrm{nc} / 3.0 /$ ) which permits unrestricted, non-commercial use, distribution and reproduction in any medium, provided the work is properly cited. 